\section{EFROTOMYCIN, A NEW ANTIBIOTIC FROM STREPTOMYCES LACTAMDURANS}

Sir:

Streptomyces lactamdurans NRRL 3802 produces a novel $\beta$-lactam antibiotic, cephamycin $C$. The chemical nature of cephamycin has been demonstrated to be 7- $\beta$-(D-5-amino-5-carboxyvaleramido) - 3 - (carbamoyloxy - methyl) - 7 - me thoxy-3-cephem-4-carboxylic acid., ${ }^{1,2)}$

During studies of the fermented broths of $S$. lactamdurans, an antibiotic was discovered with properties different from those described for cephamycin C. This new antibiotic was designated FR-02A, and later renamed efrotomycin.

Several characteristics of efrotomycin suggested that the agent was not a member of the cephamycin class of antibiotics. The broth from cultures of $S$. lactamdurans had a small amount of activity that could not be eliminated by treatment with a potent $\beta$-lactamase from Enterobacter cloacae MB2646 (HSC18410/62); cephamycin C is sensitive to hydrolysis by this enzyme. ${ }^{3)}$ Further, the enzyme-treated broth had a ratio of gram-positive to gram-negative antibacterial activity that was higher than could be expected for cephamycin $\mathrm{C}$ and for other members of the cephamycin family; these antibiotics have only slight activity against gram-positive organisms. ${ }^{4)}$ Paper chromatography of concentrated broth filtrate revealed two distinct, well-separated bioactive areas. When whole broth was extracted with equal volumes of water-immiscible solvents, all the efrotomycin migrated into the solvent phase whereas cephamycin $\mathrm{C}$ remained in the aqueous phase. The antibacterial spectrum, solvent solubility and complete indifference to the action of E. cloacae $\beta$-lactamase suggested that efrotomycin was not a member of the $\beta$-lactam group of antibiotics.
S. lactamdurans is maintained on agar slants of the following composition: blackstrap molasses, $1 \%$; Dried Brewers Yeast, $1 \%$ and Difco agar, $2.5 \%(\mathrm{pH} 7.0)$. The agar slants or lyophilized cells are used as a starter inoculum for the production of efrotomycin. To obtain optimal yields it is desirable to use two seed (inoculum) development stages. The first seed flask $(250 \mathrm{ml}$ Erlenmeyer) containing $40 \mathrm{ml}$ of medium ( $1 \%$ Primary Dried Yeast, $\mathrm{pH}$ 7.0) is inoculated from the slant culture or directly from a lyophilized tube of S. lactamdurans, and allowed to incubate for 48 hours at $28^{\circ} \mathrm{C}$ on a rotary shaker $(220 \mathrm{rpm}, 5-\mathrm{cm}$ displacement). One $\mathrm{ml}$ of the first seed is transferred to a second seed flask containing $10 \mathrm{~g} /$ liter Ardamine YEP (Yeast Products Co., Paterson, N.J., USA) at $\mathrm{pH} 7.0$ and incubated for 24 hours under similar conditions. The production medium

Table 1. Relative production of efrotomycin and cephamycin C by $S$. lactamdurans

\begin{tabular}{c|c|c|c}
\hline $\begin{array}{c}\text { Produc- } \\
\text { tion } \\
\text { medium }\end{array}$ & $\begin{array}{c}\text { Culture } \\
\text { age (hours) }\end{array}$ & \multicolumn{2}{|c}{$\begin{array}{c}\text { Antibiotic production } \\
\text { (mg/liter) }\end{array}$} \\
\cline { 3 - 4 } & $\begin{array}{c}\text { Cephamycin } \\
\text { C }\end{array}$ & Efrotomycin \\
\hline A & 96 & 240 & 147 \\
& 120 & 185 & 147 \\
B & 96 & 4 & 77 \\
& 120 & 5 & 327 \\
\hline
\end{tabular}

Medium A: As in text.

Medium B: Ingredients in \%: cornsteep liquor, 1.8; commercial grade dextrose, 5.6; Proflo cottonseed meal, 2.8; glycerol, $1.4 \mathrm{v} / \mathrm{v}$; dimethylformamide, 1.4; sodium thiosulfate, 0.05 ; and polyglycol 2000 defoamer, $0.12 \mathrm{v} / \mathrm{v}$. Adjusted to $\mathrm{pH} 7.3$ prior to sterilization. Sodium thiosulfate added aseptically from a concentrated stock solution to the sterile medium. Other conditions as in the text.

Fig. 1. Structure of antibiotics $\mathrm{X}-5108$, mocimycin and efrotomycin

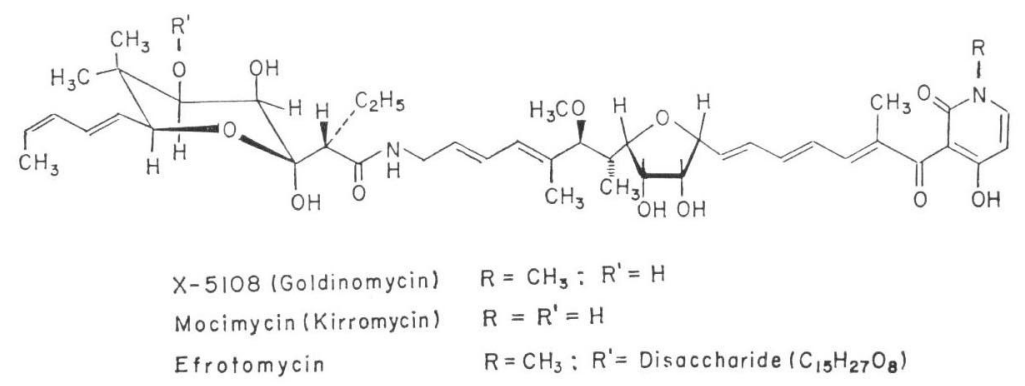


(medium A) contains the following ingredients in $\%$ : Primary Dried Yeast, 1.0; Distillers Solubles, 3.0; glycine, 0.05; L-phenylalanine, 0.3; cornstarch, 2.0; dimethyl formamide $1.0 \mathrm{v} / \mathrm{v}$; Mobile par $\mathrm{S}$ defoamer, $0.24 \mathrm{v} / \mathrm{v}$; and sodium thiosulfate, 0.05 . The $\mathrm{pH}$ was adjusted to 7.0 prior to sterilization. The thiosulfate was added aseptically from a filter sterilized concentrated stock solution to the sterile production medium. Inoculum for the production phase was $2.5 \%$ of the second stage seed and was kept at this level when large volume stirred tank fermentors were used as production vessels. Incubation was for five days at $28^{\circ} \mathrm{C}$.

The production of efrotomycin is followed by microbiological assay after extraction of the broth with chloroform at $\mathrm{pH} \mathrm{5.} \mathrm{A} \mathrm{standard} \mathrm{disc-}$ diffusion assay is used with Vibrio percolans ATCC 8461 as the assay organism, and purified samples of efrotomycin serve as the reference standards. The cephamycin $\mathrm{C}$ content of the broth was determined with the same assay organism; in this case the aqueous phase of the extraction was used after dilution in phosphate buffer, $\mathrm{pH}$ 7.0. Since the assay organism is considerably more sensitive to cephamycin $\mathrm{C}$ than to efrotomycin, a simple dilution of the unextracted broth filtrate could also be used to measure cephamycin $\mathrm{C}$ without interference from efrotomycin.

In production medium $\mathrm{A}, S$. lactamdurans NRRL 3802 produced about $150 \mathrm{mg} /$ liter of efrotomycin and $250 \mathrm{mg} /$ liter of cephamycin C. Production of both antibiotics reached their peaks between 96 and 120 hours.

Though both cephamycin $\mathrm{C}$ and efrotomycin can be produced by $S$. lactamdurans, growth media have been devised in which the production of cephamycin $\mathrm{C}$ can be greatly reduced and the level of efrotomycin increased significantly (Table

Table 2. Summary of physicochemical characteristics of efrotomycin

\begin{tabular}{|c|c|}
\hline Empirical formula & $\mathrm{C}_{59} \mathrm{H}_{88} \mathrm{~N}_{2} \mathrm{O}_{20}$ \\
\hline Molecular weight by mass spectral analysis & 1,144 \\
\hline \multicolumn{2}{|l|}{ Ultraviolet absorption } \\
\hline \multirow[t]{2}{*}{ Ammonium salt in water: } & $\lambda \max .233 \mathrm{~nm} ; \mathrm{E}_{1 \mathrm{~cm}}^{1 \%}=320$ \\
\hline & $\lambda \max .328 \mathrm{~nm} ; \mathrm{E}_{1 \mathrm{em}}^{1 \%}=180$ \\
\hline \multirow[t]{2}{*}{ Efrotomycin in pH 7.0 phosphate buffer: } & $\lambda \max .232 \mathrm{~nm} ; \mathrm{E}_{1 \mathrm{~cm}}^{1 \%}=464$ \\
\hline & $\lambda \max .327 \mathrm{~nm} ; \mathrm{E}_{1 \mathrm{em}}^{1 \%}=216$ \\
\hline \multirow[t]{3}{*}{$\begin{array}{l}\text { Representative features of nuclear } \\
\text { magnetic resonance spectrum }{ }^{1}\end{array}$} & $\begin{array}{l}\text { Doublets at } 1.21(3 \mathrm{H}), 1.31(3 \mathrm{H}), 1.74(3 \mathrm{H}) \\
\quad 4.63(1 \mathrm{H}), 5.94(1 \mathrm{H}) \text { and } 7.32(1 \mathrm{H}) \mathrm{ppm} ;\end{array}$ \\
\hline & $\begin{array}{l}\text { Overlapping signals of } 4 \text { other } \mathrm{C} \text {-methyl groups } \\
\text { at about } 0.94 \mathrm{ppm} ;\end{array}$ \\
\hline & $\begin{array}{l}\text { Singlets at } 1.65(3 \mathrm{H}), 2.02(3 \mathrm{H}), 3.15(3 \mathrm{H}) \\
3.42(3 \mathrm{H}), 3.45(3 \mathrm{H}), 3.54(3 \mathrm{H}), 3.58(3 \mathrm{H}) \\
\text { and } 4.87(1 \mathrm{H}) \mathrm{ppm} .\end{array}$ \\
\hline
\end{tabular}

Characteristic of infrared absorption spectrum (frequency in $\mathrm{cm}^{-1}$ )
Broad band: 3400

Strong bands: 1640, 1460, 1380, 1080, 1020

Prominent bands: $1550,1505,1240,1195$, $940,860,720,620$

\footnotetext{
Chromatography characteristics

Paper chromatography (isopropanol-0.1 M phosphate $\mathrm{pH} 6.0 ; 70: 30$ )

Thin-layer chromatography: Silica gel (chloroform-methanol-conc. $\mathrm{NH}_{4} \mathrm{OH} ; 80: 20: 1$ )

Sephadex LH-20: Gel filtration in methanol (as $\mathrm{NH}_{4}$ salt)

Amberlite XAD-2 chromatography: $50 \%$ isopropanol- $\mathrm{H}_{2} \mathrm{O}$ elution
}
$\mathrm{Rf}=0.9$
$\mathrm{Rf}=0.34$
$\mathrm{K}_{\mathrm{D}}=0.30$
D.V. ${ }^{3}=3.5$ to 4.0

\footnotetext{
1 Obtained at $100 \mathrm{MHZ}$ in $\mathrm{CDCl}_{3}$ as the solvent and tetramethylsilane (TMS) as the internal standard.

2 Obtained in a Nujol mull.

${ }^{3}$ D.V. = Displacement volume, i.e., the number of bed volumes required to elute the antibiotic.
} 
1). Furthermore, mutants have been selected in which either the biosynthesis of efrotomycin or cephamycin $\mathrm{C}$ has been completely eliminated, whereas the production of the second component remains unaffected. ${ }^{b)}$ These results suggest that the biosynthetic pathways for the two antibiotics are regulated independently of each other.

Efrotomycin is found both dissolved in the culture filtrate and bound to the mycelium and undissolved nutrients in the fermented broth. For isolation of the antibiotic, $400 \mathrm{ml}$ of whole broth is adjusted to $\mathrm{pH} 5$ with $\mathrm{HCl}$, two volumes of chloroform are added, mixed thoroughly and filtered through a Super-Cel pad. Sufficient water is added to speed the filtration. The filtrate is allowed to stand until the chloroform layer separates. The solvent layer is drawn off, washed twice with $500 \mathrm{ml}$ of water, dried over anhydrous $\mathrm{MgSO}_{4}$ and evaporated to dryness in vacuo. Petroleum ether, $500 \mathrm{ml}$, is added to the solid residue and the solid is collected by filtration, washed with $50 \mathrm{ml}$ of petroleum ether and air dried to yield crude efrotomycin. The antibiotic is converted to the ammonium salt by freeze drying a solution of the crude efrotomycin in $50 \mathrm{ml}$ water made basic to $\mathrm{pH} 10$ with $\mathrm{NH}_{4} \mathrm{OH}$.

Efrotomycin may be isolated from the centrifuged or filtered cake. In this case a polar watermiscible organic solvent is preferable for the first extraction. The filter cake from $400 \mathrm{ml}$ of broth is stirred in $40 \mathrm{ml}$ of acetone for 30 minutes, filtered, the filter cake washed with 15 -ml aliquots of acetone, and the filtrate and washings combined. The combined extract is evaporated under reduced pressure at $30^{\circ} \mathrm{C}$ to remove the acetone. The residue is suspended in $15 \mathrm{ml}$ of water, adjusted to $\mathrm{pH} 4.0$ with $\mathrm{HCl}$, an equal volume of hexane is added and stirred for 10 minutes. After settling, the hexane is decanted and discarded. Two more extractions with equal volumes of hexane are made, the last being colorless. The aqueous slurry is then extracted with an equal volume of chloroform. After repeating the extraction, the chloroform fractions are combined, dried over anhydrous $\mathrm{Na}_{2} \mathrm{SO}_{4}$, filtered and evaporated in vacuo to dryness.

About $100 \mathrm{mg}$ of the crude efrotomycin is dissolved in $0.5 \mathrm{ml}$ of methanol and applied to a 75 $\mathrm{ml}$ bed $(1.25 \mathrm{~cm} \times 56 \mathrm{~cm})$ of Sephadex LH-20 gel (Pharmacia Fine Chem., Inc., Piscataway, N.J.). The column is developed in methanol and the eluate is monitored with a Mecco differential refractometer. Fractions are assayed for bioactivity using disc diffusion with $V$. percolans as the indicator strain. Three mass peaks were observed in the elution profile; the third peak $\left(\mathrm{K}_{\mathrm{D}}=\right.$ $0.3)$ corresponded to the major share of the bioactivity. The fractions of this bioactive peak are combined and evaporated to yield about $40 \sim 50$ $\mathrm{mg}$ of efrotomycin. This material is brought to ultimate purity by the use of Amberlite XAD-2 resin (Rohm \& Haas Co., Philadelphia, Pa.). The product from the $\mathrm{LH}-20$ column is dissolved in $50 \%$ isopropanol-water and acidified to $\mathrm{pH} 2$ and applied to a $150 \mathrm{ml}$ bed of XAD-2 $(1.25 \mathrm{~cm} \times 112$ $\mathrm{cm})$. The column is eluted with $50 \%$ isopropanol and the eluate monitored with a refractometer and for bioactivity. The antibiotic is eluted from the column at $3.5 \sim 4.0$ column volumes of isopropanol. The bioactive fractions were combined and evaporated to dryness under reduced pressure. Efrotomycin obtained by this procedure is a pale yellow, noncrystalline solid of high purity and stable to normal handling.

A summary of the preliminary physicochemical characterization of pure efrotomycin is presented in Table 2. A detailed account of the structure elucidation will be presented in a separate communication. ${ }^{6)}$ Interpretation of the physical and chemical data leads to the assignment of efrotomycin as a new member of a recently described family of antibiotics (Fig. 1). In 1972, kirromycin, ${ }^{7)}$ mocimycin $^{8)}$ and X-5108 ${ }^{9},{ }^{10)}$ were isolated from different species of Streptomyces. Kirromycin and mocimycin were found to have the same structure, whereas $\mathrm{X}-5108$ is the Nmethylated form. ${ }^{11)}$ Efrotomycin is a disaccharide derivative of X-5108 and has many physicochemical properties in common with this antibiotic. They share characteristic U.V. absorption and distinctive NMR features. In addition, the in vitro microbiological properties are similar.

Efrotomycin has been found to be active against a variety of microorganisms many of which are particularly important pathogens for farm animals. ${ }^{12)}$ In general, the activity of efrotomycin is more pronounced against grampositive species than it is against gram-negative bacteria, which is also a characteristic of X-5108. ${ }^{10)}$ Efrotomycin is active in vivo and shows good therapeutic effectiveness in mice infected with several species of bacterial pathogens. Efficacy is obtained by oral as well as parenteral routes of administration. The antibiotic is well tolerated 
in laboratory animals; $\mathrm{LD}_{50}$ 's of $>4,000 \mathrm{mg} / \mathrm{kg}$ and $>2,000 \mathrm{mg} / \mathrm{kg}$ by oral and subcutaneous routes, respectively, have been obtained. ${ }^{12)}$ Not unexpectedly, in light of its structure, efrotomycin has shown no cross resistance with commonly used antibiotics including tetracyclines, macrolides, aminoglycosides and penicillins.

In analogy to X-5108 and mocimycin, ${ }^{13}{ }^{15}$ ) efrotomycin has been found to have good growth enhancement activity in farm animals. This property, coupled with the substantial activity against important bacterial pathogens of animals, suggests that efrotomycin might be a useful antibiotic for veterinary medicine. Detailed reports on the microbiological and therapeutic properties of the antibiotic will be discussed in a separate report.

\section{Acknowledgement}

We wish to thank Dr. Edward Inamine and Dr. RAYMOND WhITE for their helpful advice.

\author{
RICHARD WAX \\ William Maiese \\ ROY WESTON (deceased) \\ JEROME BiRnBaum
}

Merck Sharp \& Dohme Research Laboratories, Rahway, N. J. 07065, U.S.A.

(Received March 22, 1976)

\section{References}

1) Stapley, E. O.; M. Jackson, S. Hernandez, S. B. Zimmerman, S. A. Currie, S. Mochales, J. M. Mata, H. B. Woodruff \& D. Hendlin: Cephamycins, a new family of $\beta$-lactam antibiotics. I. Production by Actinomycetes, including Streptomyces lactamdurans sp. n. Antimicr. Agents \& Chemoth. 2: 122 131, 1972

2) Albers-Schonberg, G.; B. H. Arison \& J. L. Smith: New $\beta$-lactam antibiotics: Structure determination of cephamycin A and B. Tetrahedron Letters 1972-29: 2911 2914, 1972
3) Onishi, H. R.; D. R. DAOUSt, S. B. ZimMERMAN, D. Hendlin \& E. O. Stapley: Cefoxitin, a semisynthetic cephamycin antibiotic: Resistance to $\beta$-lactamase inactivation. Antimicr. Agents \& Chemoth. 5: 38 48, 1974

4) Miller, A. K.; E. Celozzi, B. A. Pelak, E. O. Stapley \& D. Hendlin: Cephamycins, a new family of $\beta$-lactam antibiotics. III. In vitro studies. Antimicr. Agents \& Chemoth. 2: $281 \sim 286,1972$

5) Lago, B. \& E. Cross: Unpublished observations.

6) Dewey, R. \& G. Albers-Schonberg: In preparation.

7) Wolf, H. \& H. ZAHNER: Metabolic products of microorganisms. 99. Kirromycin. Arch. Mikrobiol. 83: 147 154, 1972

8) Vos, C. \& P. E. J. VerwIEL: Structure of the new antibiotic mocimycin (MYC8003): Chromophore and furopyranone fragment. Tetrahedron Lett. 1973-30: 2823 2826, 1973

9) Maehr. H.; J. F. Blount, R. H. Evens, M. Leach, J. W. Westley, J. W. Williams, T. H. Stempel \& G. Buchi: Antibiotic X5108. II. Structure of goldinono-1,4-lactone-3,7-hemiketal, a degradation product of the antibiotic. Helv. Chim. Acta 55: $3051 \sim 3054,1972$

10) Berger, J.; H. H. Lehr, S. Teitel, H. Maehr \& E. GrunberG: A new antibiotic X-5108 of Streptomyces origin. I. Production, isolation and properties. J. Antibiotics 26: 15 22, 1973

11) Maehr. H.; M. Leach, L. YarmchuK \& A. STEMPEL: Antibiotic X-5108. V. Structures of antibiotic X-5108 and mocimycin. J. Am. Chem. Soc. 95: 8449 8450, 1973

12) Frost, B. M.; M. E. Valiant, B. Weissberger \& E. L. Dulaney: Antibacterial activity of efrotomycin. J. Antibiotics, in press.

13) Berger, J.; Antibiotic X-5108 for stimulating growth. U.S. Patent $\# 3,657,421$, April 18, 1972

14) Marusich, W. L.; E. F. Ogrinz \& M. MiTROVIC: A new antibiotic, X-5108, for improved growth and feed conversion in poultry. Poul. Sci. 53: 936 945, 1974

15) Van Eek, T. \& R. Beukers: German Patent \#2,406,164, February 1974 